\title{
Integration of Real-Time Demand Information and Spare Parts Distribution Planning for the Optimization of Spare Parts Supply in After-Sales Service Networks
}

\author{
Martin Thormann \\ Graduate School of Logistics, Faculty of Mechanical Engineering, \\ TU Dortmund University, 44227 Dortmund, Germany \\ Email: martin.thormann@iml-stipendiat.fraunhofer.de
}

\begin{abstract}
Accurate spare parts demand planning and effective distribution planning is essential for providers of after-sales services in the machine and plant engineering industry to ensure high spare parts availability for maintenance and failure orders (callouts) at a reasonable cost. Low spare parts availability is primarily the result of high uncertainty in spare parts demand, leading to misallocation of parts within aftersales service networks. The lack of spare parts availability causes equipment downtime, resulting in customer dissatisfaction and possible penalty costs for after-sales service providers, if response times are contractually fixed. This paper proposes an approach and planning methods for integrating real-time status information about equipment utilization and service conditions to determine optimal spare parts stocking strategies. For this purpose, spare parts stocking strategies and ordering policies for application in after-sales service networks are analyzed. Furthermore, a binary linear optimization model is developed for the assignment of stocking strategies to spare parts based on real-time demand information of the equipment to be serviced. This method uses data provided by an internationally operating elevator company.
\end{abstract}

Keywords: after-sales service, demand planning, distribution planning, elevator industry, inventory management, spare parts management

\section{INTRODUCTION}

High spare parts availability is essential for providers of after-sales services to efficiently carry out equipment maintenance, troubleshooting, or repair. The spare parts supply is fulfilled via an after-sales service network composed of central (CDC) and regional distribution centers (RDC), branches, and service cars or service technicians, upon which distribution chains are built (see Figure 1). This type of after-sales service network structure is very common in the machine and plant engineering industry, particularly the elevator industry. The spare parts demand and distribution planning requirements in after-sales service networks can vary tremendously among different industries. Figure 2 shows the relevant characteristics describing aftersales service networks and network characteristic forms considered in this research work.

In the networks considered in this research work, aftersales service providers offer product services by undertaking contractually specified maintenance and troubleshooting activities for an annual rate (cf. Dombrowski \& Winnefeld, 2012). Due to the increasing scope of such services, they are offered for both their own and third-party equipment, resulting in a variety of equipment types to be serviced (Baader et al., 2006). Further, two main customer types exist: 1) customers who operate very few or a single number of equipment at a particular customer location; these are mostly private customers; and 2) customers who operate at large-scale locations with a large number of equipment at one location; these are mostly business customers. Due to the immobility of the equipment, maintenance and repair is solely conducted on-site at the customer location. Therefore, service technicians require service cars for servicing this equipment and holding spare part inventories. Response time requirements in these networks are mainly non critical due to frequently redundant equipment application; however, a small portion of service contracts specifies highly critical response time requirements. The existing spare parts are mainly small parts, which are shipped via courier express parcel (CEP) services to the desired location by single shipments, since the demand of the decentralized entities is low and sporadic (cf. Muhammad Naiman Jalil, 2011). The organizations of concern are large-scale enterprises that operate hundreds of branches and deploy thousands of service technicians to achieve appropriate customer proximity, resulting in very decentralized network structures (cf. Dekker et al., 2013; Muhammad Naiman Jalil, 2011). Hence, a small number of central entities, such as central and regional distribution centers, serve a large number of branches and service technicians

To maintain high spare parts availability with a reasonable logistics cost in these large scale network structures, providers of after-sales services need to adequately forecast spare parts demand and effectively make appropriate decisions for the various network entities - such as CDCs, RDCs, branches, and service cars - regarding sourcing, allocating, and disposing of spare parts. These planning tasks can be aligned with demand planning and distribution planning in the supply chain management task model, developed by Kuhn and Hellingrath (2002). Since demand planning is the fundamental basis for subsequent stocking decisions, such as where and how much to stock and when to order, after-sales service provider can only make decisions by integrating both planning tasks (cf. Ihde 
et al., 1999; Schuh et al., 2013; Klug, 2010; Hayashi et al., 2009). The definitions of these two planning tasks originate from conventional logistics networks, such as retail or production networks, but they are appropriate in the context of after-sales service networks. However, in after-sales service networks, demand and distribution planning of spare parts are even more complex planning tasks, particularly in highly service-oriented manufacturing industries such as the elevator industry. In this industry, the equipment to be serviced (equipment portfolio) comprises equipment from several decades and different manufacturers, leading to high equipment heterogeneity (cf. Hertz \& Finke, 2011; Dispan, 2007). Moreover, new installations, high cancellation rates of service contracts, and the consolidation of markets due to mergers and acquisition activities lead to a steady fluctuation in the equipment portfolio (cf. Blakeley et al., 2003; Baumbach, 2004). Consequently, after-sales service providers need to plan for numerous parts in severely uncertain and volatile markets (cf. Cohen et al., 2006; Hertz $\&$ Finke, 2011). Therefore, after sales service providers cannot make decisions based solely on historical demand data (cf. Niggeschmidt, 2010; Ihde et al., 1999; Thormann, 2014). Additionally, the highly decentralized network structures increase the complexity in determining optimal decisions that minimize the total logistics cost for the entire service network, such as shipping, holding, handling, or ordering costs, since strong reciprocity exists among the planning decision of each network entity.

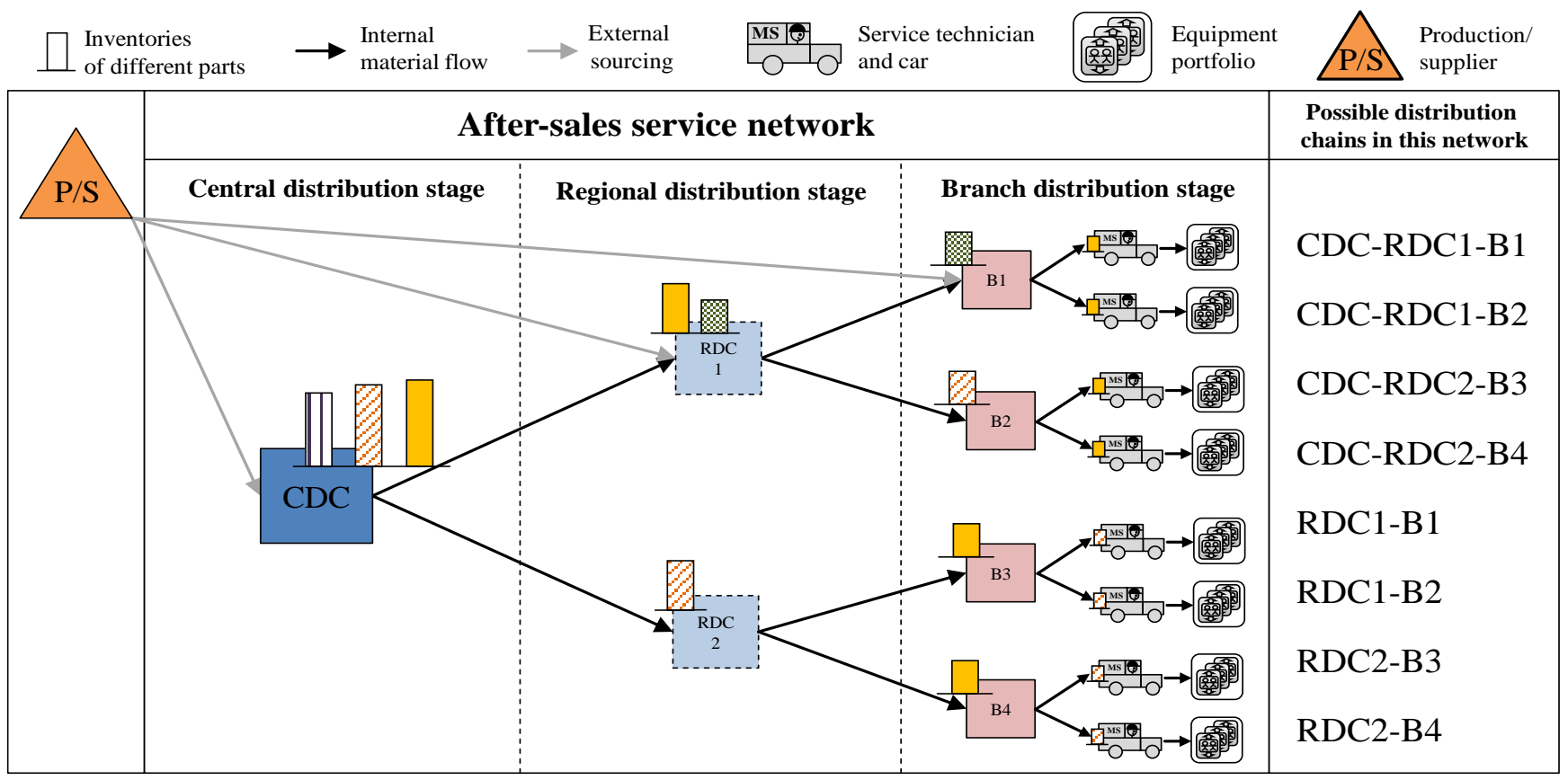

Figure 1 After-sales service network and distribution chains

\begin{tabular}{|c|c|c|c|c|c|}
\hline \multicolumn{2}{|c|}{ Characteristic } & \multicolumn{4}{|c|}{ Form } \\
\hline \multirow{2}{*}{$\begin{array}{l}\text { Service specific } \\
\text { characteristics }\end{array}$} & Maturity level of services & Parts services & Prod & & Operator Services \\
\hline & Scope of service & \multicolumn{2}{|c|}{ Own equipment } & \multicolumn{2}{|c|}{ Own and third-party equipment } \\
\hline \multirow{4}{*}{$\begin{array}{l}\text { Equipment and } \\
\text { industry specific } \\
\text { characteristics }\end{array}$} & Customer base & Private customer base & \multicolumn{2}{|c|}{ Mixed customer base } & Business customer base \\
\hline & Location of service provision & \multicolumn{2}{|c|}{ On-site } & \multicolumn{2}{|c|}{ Service station } \\
\hline & Response time requirements & Noncritical & \multicolumn{2}{|c|}{ Partly critical } & Highly critical \\
\hline & Parts & \multicolumn{2}{|c|}{ Small parts } & \multicolumn{2}{|c|}{ Large parts (bulky) } \\
\hline \multirow{2}{*}{$\begin{array}{l}\text { Organizational } \\
\text { specific } \\
\text { characteristics }\end{array}$} & Size of organisation & \multicolumn{2}{|c|}{ Small- and medium-sized enterprises (SME) } & \multicolumn{2}{|c|}{ Large-scale enterprise } \\
\hline & Organisational structure & \multicolumn{2}{|c|}{ Decentralized } & \multicolumn{2}{|c|}{ Centralized } \\
\hline
\end{tabular}

Figure 2 Network characteristics

\section{SPARE PARTS DISTRIBUTION PLANNING IN AFTER SALES SERVICE NETWORKS}

Research in spare parts distribution planning in the last decades has focused on different aspects of distribution planning, such as inventory control. However, approaches to inventory management in multi-echelon networks that introduce the subject of spare parts allocation and disposition are rare. The next section briefly introduces some of these approaches. Next, relevant spare parts stocking concepts and inventory policies are briefly presented as a theoretical foundation for this paper. 


\subsection{Inventory Management Approaches for Multi-Echelon Networks}

The approach of Multi-Echelon Technique for Recoverable Item Control (METRIC) is most frequently cited in research on spare parts inventory management in multi-echelon networks and applied in practice. This method was developed by Sherbrooke (1968) for repairable items of the Air Force that tend to be expensive and low in demand. It is the basis for several multi-echelon models used in military services. The METRIC approach considers inventory systems with one central warehouse and several depots, and calculates for every item the optimal stock level for several bases with a one-for-one replenishment policy (cf. Sherbrooke, 2004; Muhammad Naiman Jalil, 2011). An extension of this mathematical model known as the MOD METRIC model was developed by Muckstadt (1973). It calculates base and depot spare stock levels with explicit consideration of hierarchical parts structures, describing logistics relationships between components and final products. Slay (1984) obtained a better approximation by deriving a term for the variance of the number of items in repair with a negative binomial distribution. This method is called the VARI-METRIC (Muhammad Naiman Jalil, 2011). Graves (1985) adjusted this approach by developing a derivation that assumes constant resupply times. Sherbrooke (1986) analyzed this derivation and showed that the VARI-METRIC model improves upon the MODMETRIC model. While the previous work mostly considered one-for-one ordering policies, several studies have focused on handling batch ordering policies (e.g. Svoronos \& Zipkin, 1988 or Axsäter, 2003). Although the METRIC approach and its extensions are clearly the most applied inventory management approaches for multi-echelon networks, they are solely applicable for a restricted variety of network configurations with a priori determined ordering policies. They do not consider the specific requirements of after-sales service networks, and can only be applied to a limited number of network forms. Nevertheless, part of this approach, the METRIC approximation, is appropriate for the developed distribution planning method and has therefore been integrated.

\subsection{Spare Parts Stocking Concepts for Multi- Echelon After-Sales Service Networks}

Spare parts stocking concepts are not consistently defined in the literature. This section attempts to illustrate and categorize the main approaches for stocking spare parts within multi echelon after-sales service networks. The most widely applied stocking concepts in the spare parts domain are fully decentralized and fully centralized stocking. Decentralized stocking has the advantage of short reaction times due to proximity of inventories to customers. However, it is accompanied by high inventories, particularly in highly decentralized networks, such as the after sales service networks considered in this paper. Centralized stocking has the advantage of achieving potentials in stocking and source pooling, but it is associated with longer response times. The selective stocking concept combines the advantages of both the centralized and decentralized concepts: fast moving or critical parts are stored on lower echelons, and slow-moving or non critical parts on higher echelons (cf. Pfohl, 2010; Vahrenkamp \& Kotzab, 2012;
Klug, 2010; Meierbeck \& Grossmann, 2012). Further approaches that are considered in the literature are the consignation storage concept, the just-in-time concept (JIT), and the vendor managed inventory concept (VMI) (cf. Schuh et al., 2013; Surjandari et al., 2010). In the network forms regarded in this research work, consignation storage can be applied for customers with large bases and highly critical response time requirements. However, the VMI and JIT concepts are not appropriate for the considered aftersales service networks, since VMI requires strong and stable collaboration between service providers and customers and JIT delivery schedules. Despite the applicability of the illustrated concepts, the exact definition and embodiment of these concepts, including ordering policies and supply relations between the echelons, are not defined in the literature.

\subsection{Spare Parts Ordering Policies for After- Sales Service Networks}

Inventory control systems can be separated into continuous review and periodic review policies. Continuous review policies are accompanied by continuous monitoring of the inventory position, meaning that an order is placed whenever the inventory position decreases to a predetermined level. Periodic review policies check inventory positions only at a certain point in time, where the intervals between these reviews are generally constant. For items with low demand, and thus for spare parts, continuous review policies are the most appropriate. The most common continuous ordering policies are the $(\mathrm{s}, \mathrm{Q})$ policy and $(\mathrm{s}, \mathrm{S})$ policy. When applying $(\mathrm{s}, \mathrm{Q})$ policy, a batch quantity of size $\mathrm{Q}$ or a multiple of $\mathrm{Q}$ is ordered if the inventory position is equal to or lower than the reorder point $\mathrm{s}$. The $(\mathrm{s}, \mathrm{S})$ policy works in the same way; however, after the inventory position falls below the reorder point $\mathrm{s}$, it is ordered up to the maximum level $\mathrm{S}$, which needs to be additionally defined. These two inventory policies only differ when the reorder point is not exactly hit. An alteration of the $(\mathrm{s}, \mathrm{S})$ policy, the $(\mathrm{S}-1, \mathrm{~S})$ policy, also called base stock policy, will always order unless there is no demand (Axsäter, 2006). This ordering policy is appropriate for high-cost and low demand items (Sherbrooke, 1986). Consequently, the (s,Q) policy and $(\mathrm{S}-1, \mathrm{~S})$ policy are the ordering policies that are most suitable for spare parts in after-sales service networks and are considered for the solution approach (cf. Biedermann, 2008).

\section{INTEGRATED SPARE PARTS DISTRIBUTION PLANNING APPROACH}

For the described spare parts distribution planning task, an integrated approach with appropriate planning methods has been developed, as shown in Figure 3. The developed method consists of three main steps and integrates real-time status information about equipment utilization and service conditions for enhancing the demand information basis for subsequent distribution planning decisions as presented by Thormann (2014). The general idea of this framework will be explained in this section. After that, certain aspects of the developed methodology will be introduced. 
In the first step of the development of the distribution planning approach, spare parts stocking concepts have been analyzed to determine appropriate stocking strategies for the considered multi echelon after-sales service networks. In this context, spare parts stocking strategies are defined as a readily designed combination of stocking, sourcing, and disposal decisions of all autonomously acting network entities as well as the corresponding supply relationships of a distribution chain. These stocking strategies have to be applied for each spare part within the after-sales service network. By matching appropriate stocking strategies with the network-specific requirements, a strategy tool kit with applicable stocking strategies alternatives has been developed, which can be applied by each distribution chain. However, after sales service providers need to consider all decisions of each part and each distribution chain simultaneously to find stocking strategies that minimize the total logistics cost for the considered network. This is because strong reciprocity exists between the decisions for each part and the distribution chain. For instance, following the notation of Figure 1, the cost-optimal stocking strategy for CDC RDC1 B1 might be to stock a particular part in the branch storage, whereas the network wide cost-optimal stocking strategy considering all distribution chains would be to stock this part in the central distribution center and to supply the branches on demand. Moreover, capacity restrictions exist at the branch and mobile storage locations. Therefore, only a set of spare parts has to be stored at the branch storage stage, which minimizes the network-wide logistics costs. For this reason, making these decisions successively or in an isolated manner might result in a loss of pooling potential and higher logistics costs. Thus, aftersales service providers need to simultaneously consider all possible decision alternatives within the network to satisfy each network entity in terms of the required service level and in minimizing the total logistics costs. Due to the variety of spare parts, network entities, and available decisions, an optimization model is used to find stocking strategies for each spare part and distribution chain. For the integration of the developed stocking strategies into an optimization model, the stocking strategies have been logically broken down to echelon-dependent inventory management decision alternatives (EDIMDA). EDIMDA will be defined as applicable combinations of sourcing, stocking, and disposal decision alternatives that can be taken on each distribution stage (echelon) for each part. They determine whether to stock a spare part or not, what inventory policy to choose, and from where to source a spare part for each network entity. Since EDIMDA represent decisions for only one part and echelon, it is possible to quantitatively evaluate these decisions and model them in the optimization approach.

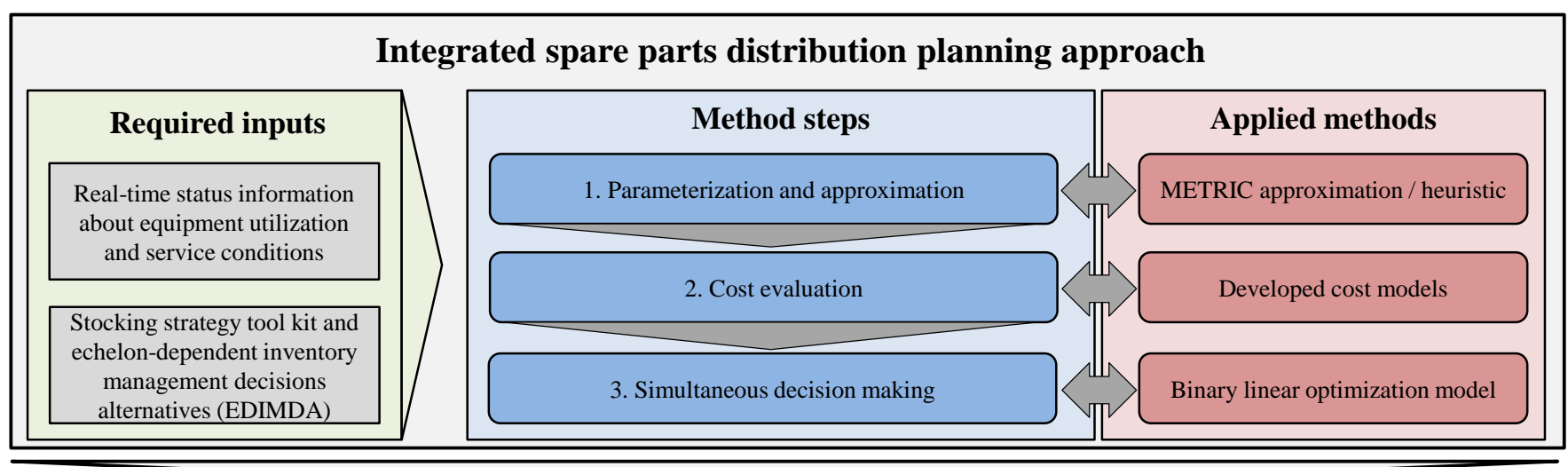

Cost-optimal EDIMDA for all network entities under specific consideration of service levels, time, and capacity constraints

Figure 3 Integrated Spare Parts Distribution Planning Approach

Based on the integration of real-time demand information and the EDIMDA, the integrated spare parts distribution planning approach follows three main steps. In the first step, all considered EDIMDA are parameterized for each stocking location and spare part with a developed heuristic applying the METRIC approximation (cf. Muckstadt \& Sapra, 2010 or Axsäter, 2006). The parameterization facilitates the quantitative evaluation of each EDIMDA with developed cost models in the second step. The final step involves a binary linear optimization model that simultaneously considers all parameterized and evaluated EDIMDA of the parts for each stocking location in the network by minimizing total cost and considering capacity and time constraints.

Since this approach has been developed for tactical distribution planning, the method should be applied after an interval of several months, after significant change in demand has occurred. For this, service providers need to retrieve the real time equipment status information and forecast the demand as presented by Thormann (2014). With the updated real time demand information, the three steps of the distribution planning method should be initiated. After that, service providers need to check the distribution planning results with the current distribution plan and implement appropriate adaptation measures, such as the adaptation of stocking policies or disposal parameters, or the reallocation of spare parts within the after-sales service network.

\subsection{Spare Parts Stocking Strategies Tool Kit for Multi-Echelon After-Sales Service Networks}

To determine optimal stocking strategies for each spare part and distribution chain, a stocking strategy tool kit for after sales service networks has been developed (see Figure 4). The strategy tool kit is required to reduce the solution space for the optimization model, by limiting decisions to 
only those strategy alternatives that are applicable for after sales service networks. Therefore, ineffective stocking strategies, corresponding to the definition given in the previous section, will not be considered. For instance, when considering a two echelon distribution chain with a CDC and a branch, it is not sensible to apply a batch ordering $(\mathrm{s}, \mathrm{Q})$ policy at the branch, when it sources a part at the CDC due to the low demand of the decentralized entities.

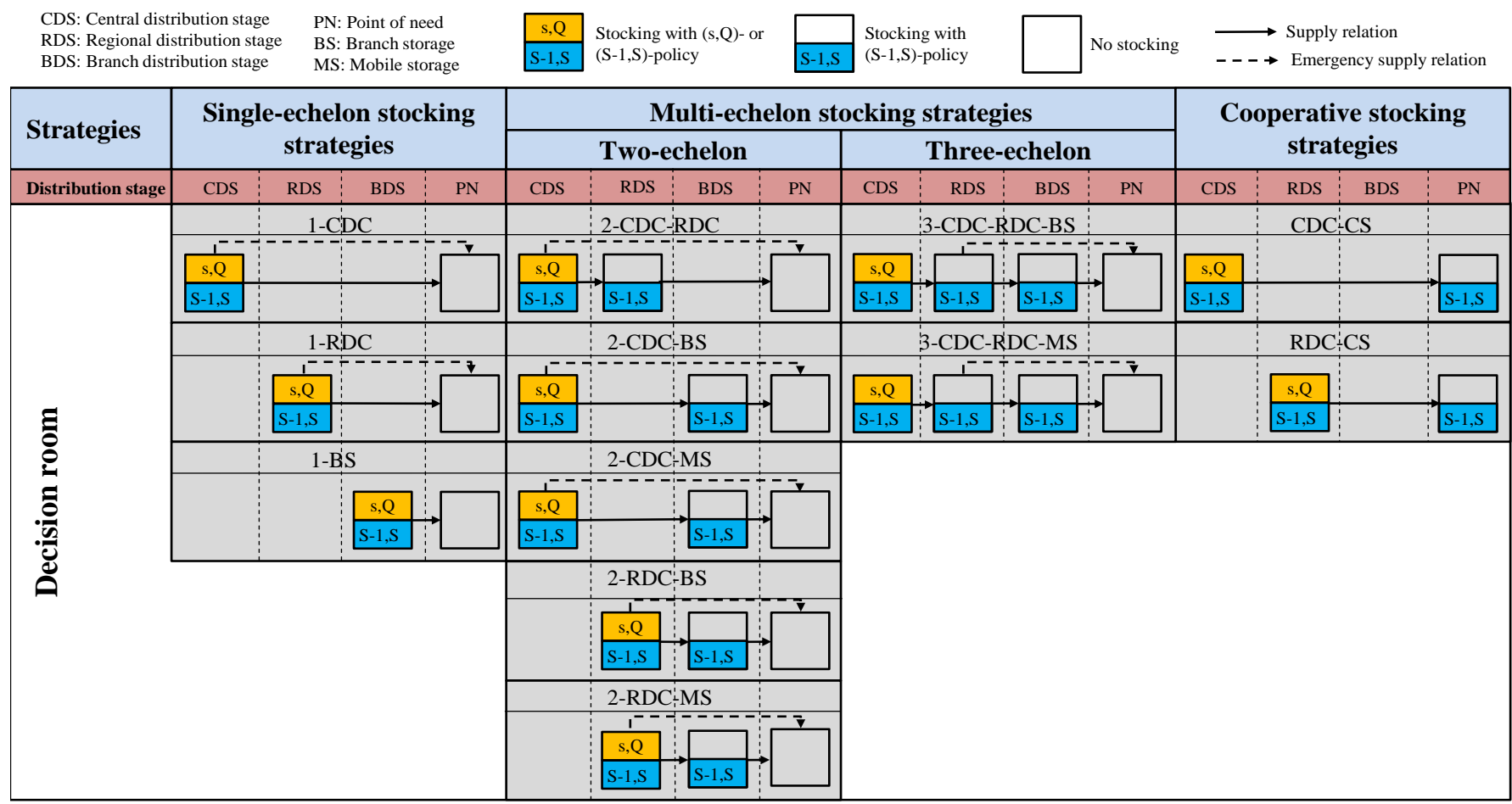

Figure 4 Spare Parts Stocking Strategy Tool Kit for Multi-Echelon After-Sales Service Networks

The strategy tool kit considers three distribution stages, which consist of the central, regional, and branch distribution stages. The latter has two storage location types: the branch storage location and the mobile storage locations of the respective service cars. These two stocking location types comprise one distribution stage, since the hinterland of a branch is geographically restricted and service technicians are usually able to access both storage locations. Therefore, it is not economical for a branch to store a part at both the branch and mobile storage locations. The stocking strategies refer to only one part and one distribution chain, following the definition in Figure 1, and pursue the general objective to maximize the pooling potentials and achieve economies of scale in the considered networks. In after-sales service networks, pooling potentials can be best achieved in sourcing and stocking (Cohen et al., 2006). Transportation pooling potentials on the distribution side cannot be achieved in after-sales service networks, since the demand of the decentralized entities is low and sporadic and transportation is carried out by a CEP service provider (Muhammad Naiman Jalil, 2011). Thus, for maximizing pooling potentials in stocking and sourcing, only the first stage of a distribution chain can source from an external supplier and apply the batch-ordering policy to supply down-stream connected network entities. It is assumed that all down stream connected network entities source the part at the internal upstream distribution stage to maximize sourcing and stocking pooling potentials. This assumption is valid since this research work considers after sales service networks of one corporation. The stocking strategies can be separated into single-echelon, multi-echelon, and cooperative stocking strategies and are briefly explained in the following:

- Single-echelon strategies: These strategies allow a spare part to be stocked at only one stage of a distribution chain and are most likely to be applied for slow moving or non critical parts within a distribution chain.

- Multi echelon strategies: These strategies allow the respective part to be stocked at two or three stages and are appropriate for fast moving or critical parts or for distribution chains with long lead times.

- Cooperative stocking strategies: These include consignment stocking, where a part is stocked at the customer location and supplied by the internal central or regional distribution center. These strategies are only for highly critical parts at customer bases with a large amount of equipment and high response time requirements.

Regardless of the number of distribution stages of the respective strategy, the regional distribution centers serve as the first distribution stage solely for parts that are exclusively required by their down-stream connected branches, for example, for regionally required parts, to avoid the loss of pooling potential. Similarly, a branch acts as the first distribution stage only if the respective part is exclusively required in this branch. 


\subsection{Decomposition to Echelon-Dependent Inventory Management Decision Alternatives}

The stocking strategies of the developed tool kit have been logically decomposed to echelon-dependent inventory management decision alternatives (EDIMDA). They define all possible combinations of sourcing, stocking, and disposal decisions for each distribution stage. EDIMDA can be integrated in the optimization model, which will then choose the optimal decision alternative for each storage location of a distribution stage. The different EDIMDA compositions of the respective network entities of a distribution chain are able to build any combination of the stocking strategy tool kit.

The EDIMDA and their respective model indices are presented in Figure 5, where the decision alternatives of the central, regional, and branch distribution stages are shown. The central distribution stage has the fewest number of alternatives, namely three, since this stage can only source from external suppliers. The regional distribution stage has four decision alternatives. The largest number of alternatives is in the branch distribution stage, since numerous sourcing alternatives exist and parts can be stored in either the branch or mobile stocking locations. The cooperative stocking strategies are not broken down in EDIMDA since they require strong collaboration between service providers and customers and cannot be determined just by an optimization model. However, if desired, they can be easily defined and added to EDIMDA and modeled in the optimization approach. The deduced and defined EDIMDA are depicted in Figure 5.

\begin{tabular}{|c|c|c|c|c|c|c|}
\hline$\longrightarrow \begin{array}{l}\text { Sourcing/replenishment } \\
\text { decision }\end{array}$ & $\begin{array}{l}\text { Internal / external } \\
\text { supplier }\end{array}$ & 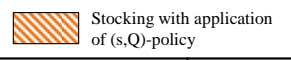 & \multicolumn{2}{|c|}{$\begin{array}{l}\text { Stocking with application } \\
\text { of }(\mathrm{S}-1, \mathrm{~S}) \text {-policy }\end{array}$} & \multirow{2}{*}{\multicolumn{2}{|c|}{$\begin{array}{c}\text { No stocking } \\
\begin{array}{c}\text { Branch distribution } \\
\text { stage (BDS) }\end{array}\end{array}$}} \\
\hline \multirow{2}{*}{$\begin{array}{l}\text { Model } \\
\text { index }\end{array}$} & \multirow{2}{*}{$\begin{array}{l}\text { Echelon-dependent inventory management decision alternatives } \\
\text { (EDIMDA) }\end{array}$} & \multirow{2}{*}{$\begin{array}{l}\text { External } \\
\text { supplier }\end{array}$} & \multirow{2}{*}{$\begin{array}{c}\text { Central } \\
\text { distribution } \\
\text { stage (CDS) }\end{array}$} & \multirow{2}{*}{$\begin{array}{c}\text { Regional } \\
\text { distribution } \\
\text { stage (RDS) }\end{array}$} & & \\
\hline & & & & & BS & MS \\
\hline $\mathrm{D}_{\mathrm{CDS} 1}$ & Stocking with replenishment of supplier and application of (s/Q)-policy & & & & & \\
\hline $\mathrm{D}_{\mathrm{CDS} 2}$ & Stocking with replenishment of supplier and application of (S-1/S)-policy & & -2 & & & \\
\hline $\mathrm{D}_{\mathrm{CDS} 3}$ & No stocking & & & & & \\
\hline $\mathrm{D}_{\mathrm{RDS} 1}$ & Stocking with replenishment of supplier and application of (s/Q)-policy & & & $+\mathbb{1}$ & & \\
\hline $\mathrm{D}_{\mathrm{RDS} 2}$ & Stocking with replenishment of supplier and application of (S-1,S)-policy & & & -2 & & \\
\hline $\mathrm{D}_{\mathrm{RDS} 3}$ & Stocking with replenishment of central distribution center and application of (S-1/S)-policy & & & -2 & & \\
\hline $\mathrm{D}_{\mathrm{RDS} 3}$ & No stocking & & & & & \\
\hline $\mathrm{D}_{\mathrm{BDS} 1}$ & No stocking and sourcing on demand from supplier & & & & & \\
\hline $\mathrm{D}_{\mathrm{BDS} 2}$ & No stocking and sourcing on demand from central distribution center & & & & & \\
\hline $\mathrm{D}_{\mathrm{BDS} 3}$ & No stocking and sourcing on demand from regional distribution center & & & & & \\
\hline $\mathrm{D}_{\mathrm{BDS} 4}$ & Stocking in branch storage with replenishent of supplier and application of (s/Q)-policy & & & & 2 & $\mathbb{Q}$ \\
\hline $\mathrm{D}_{\mathrm{BDS} 5}$ & Stocking in branch storage with replenishent of supplier and application of (S-1,S)-policy & A & & & 2 & t \\
\hline $\mathrm{D}_{\mathrm{BDS} 6}$ & Stocking in branch storage with replenishent of central distribution center and application of (S-1,S)-policy & & 2 & & & \\
\hline $\mathrm{D}_{\mathrm{BDS} 7}$ & Stocking in branch storage with replenishent of regional distribution center and application of (S-1,S)-policy & & & & M.l/ & \\
\hline $\mathrm{D}_{\mathrm{BDS} 8}$ & Stocking in mobile storage with replenishment of central distribution center and application of (S-1,S)-policy & & Q & & & R \\
\hline $\mathrm{D}_{\mathrm{BDS} 9}$ & Stocking in mobile storage with replenishment of regional distribution center and application of (S-1,S)-policy & & & $\Delta$ & & W \\
\hline
\end{tabular}

Figure 5 Echelon-Dependent Inventory Management Decision Alternatives (EDIMDA)

\subsection{Steps of the Distribution Planning Method}

After the required inputs and the general idea of the integrated distribution planning approach are illustrated, this section focuses on introducing the different steps of the method. Steps 1 and 2 are briefly described in section 3.3.1; however, it is not in the scope of this paper to present the entire parameterization and approximation heuristic and the respective EDIMDA cost models. Section 3.3.2 presents the third step, the optimization model for integrating EDIMDA.

\subsubsection{Steps 1 and 2: Approach for Parameterization, Approximation, and Cost Evaluation}

To determine the optimal stocking strategy for each distribution chain and spare part that minimizes the total logistics costs of the after sales service network, the optimization model needs to determine the right EDIMDA combinations of each stage of a distribution chain for a spare part. The determination requires parameterization and evaluation of the EDIMDA. Therefore, an approach for evaluating the different decision alternatives has been developed, since the cost of the respective EDIMDA depend on whether a network entity will stock a part or not, where it sources a part, and what ordering policy and disposition parameters it uses. Depending on the sourcing decision and the accompanying replenishment time, the disposition parameters of the respective ordering policy will be parameterized using the METRIC approximation (cf. Muckstadt \& Sapra, 2010 or Axsäter, 2006). The METRIC approximation enables the approximation of lead time and the evaluation of average inventories and backorders. The approximation is integrated in a developed heuristic, which parameterizes the EDIMDA based on the real-time demand information, such that a certain service level is achieved. The parameterized EDIMDA can then be evaluated with cost models, which consider process cost, including handling, ordering, transportation, and provisioning costs as well as process-independent costs, such as holding and contract penalty costs. The parameterized and evaluated EDIMDA for each network entity and spare part serve as the 
input parameter for the optimization model presented in the next section.

\subsubsection{Steps 3:Optimization Model for the Integration of EDIMDA}

The developed optimization approach is a binary linear model, where the objective function is to minimize the total costs for each spare part and distribution stage under specific consideration of lead times and capacity constraints. The respective cost functions are linear and consider all cost elements as described in section 3.3.1. There are four types of binary variables. Three variable types represent EDIMDA for each distribution stage and spare part-one variable type for each distribution stage. The fourth variable type represents the decision to open or not open the branch storage location. This decision is inevitable for the considered networks even though strategic network design decisions are already taken on the tactical planning level, because the branch hinterland and equipment density varies strongly among different branches. For instance, for a branch with a large hinterland, low equipment density, and widely dispersed customers, running even a small branch storage might not be economical, since the travel times and travel costs for service technicians would be far too expensive. However, the equipment density might change in the tactical planning horizon so that opening the branch storage might be an option for the next planning period. Since the main objective of this paper is to illustrate an approach instead of the specific deduction and explanation of the steps of the method, the optimization model is presented for a two echelon network with one central distribution center and a branch distribution stage, consisting of branches with branch and mobile storage locations and where both distribution stages can be supplied by an external supplier. This model can easily be extended and applied for three echelon networks by adding the required constraints. The variables of the model are denoted in Table 1.

Table 1 Notation of the Optimization Model

\begin{tabular}{|c|c|c|}
\hline Sets & Parameters & Variables \\
\hline $\begin{array}{l}\text { - Supplier: } s=1, \ldots, S \\
\text { - Central distribution center: } c \\
=1, \ldots, C \\
\text { - Regional distribution center: } \\
r=1, \ldots, R \\
\text { - Branches: } b=1, \ldots, B \\
\text { - Spare parts: } p=1, \ldots, P \\
\text { - EDIMDA: } d=1, \ldots, D \\
\text { o For CDS: DCDS } \\
\text { o For RDS: } D_{R D S} \\
\text { o For BDS: } D_{B D S}\end{array}$ & 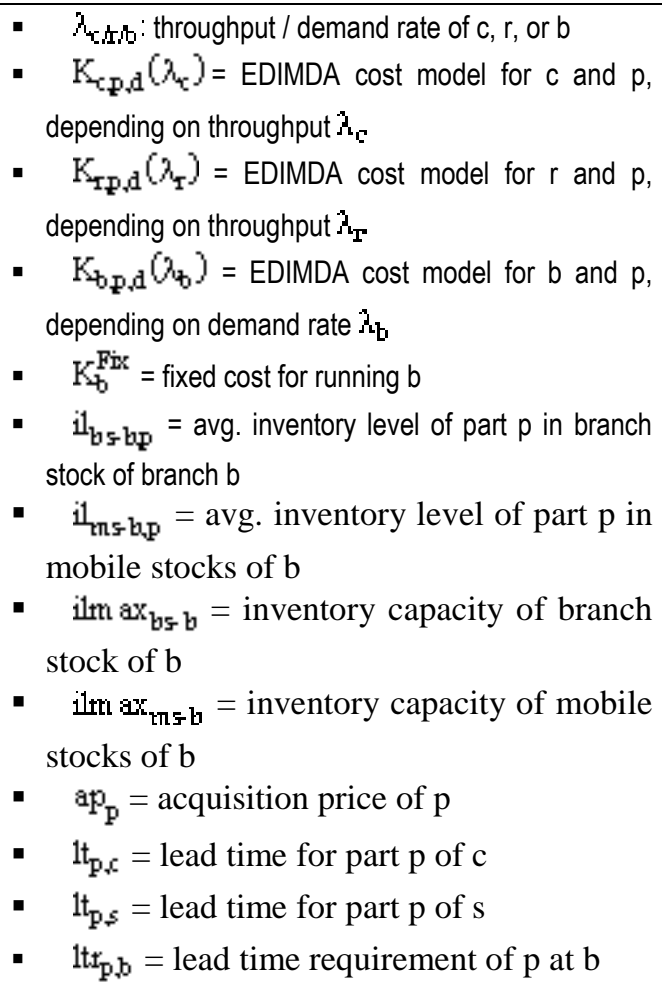 & $\begin{array}{ll}\text { - } & \mathrm{x}_{\mathrm{b}}=\left\{\begin{array}{c}1, \text { if stocking location of } \mathrm{b} \text { is open } \\
0\end{array}\right. \\
\text { - } & \mathrm{x}_{\mathrm{CD}, \mathrm{d}}=\left\{\begin{array}{c}1, \text { if } \mathrm{c} \text { applies EDIMDA } \mathrm{d} \text { for } \mathrm{p} \\
0\end{array}\right. \\
\text { - } & \mathrm{x}_{\mathrm{T} \downarrow \mathrm{d}}=\left\{\begin{array}{c}1, \text { if } \mathrm{r} \text { applies EDIMDA } \mathrm{d} \text { for } \mathrm{p} \\
0\end{array}\right. \\
\text { - } & \mathrm{x}_{\mathrm{b} \mathrm{d}}=\left\{\begin{array}{c}1, \text { if } \mathrm{b} \text { applies EDIMDA } \mathrm{d} \text { for } \mathrm{p} \\
0\end{array}\right.\end{array}$ \\
\hline
\end{tabular}

Objective Function (Total):

$\sum_{c} \sum_{p} \sum_{d \in D_{c}} k_{c, p, d}\left(\lambda_{c}\right) \cdot x_{c p, d}+\sum_{r} \sum_{p} \sum_{d \in D_{r}} k_{r, p, d}\left(\lambda_{r}\right) \cdot x_{r, p, d}+\sum_{b} x_{b} \cdot k_{b}^{F i x}+\sum_{b} \sum_{p} \sum_{d \in D_{b}} k_{b, p, s}\left(\lambda_{d}\right) \cdot x_{b, p, d}$

$\rightarrow$ Min

Objective Function for a Two-Echelon (CDC-B):

$\sum_{c} \sum_{\mathrm{p}} \sum_{\mathrm{d} \in \mathrm{D}_{\mathrm{c}}} \mathrm{K}_{\mathrm{c}, \mathrm{p}, \mathrm{d}}\left(\lambda_{\mathrm{c}}\right) \cdot \mathrm{x}_{\mathrm{c}, \mathrm{p}, \mathrm{d}}+\sum_{\mathrm{b}} \mathrm{x}_{\mathrm{b}} \cdot \mathrm{K}_{\mathrm{b}}^{\mathrm{Fix}}+\sum_{\mathrm{b}} \sum_{\mathrm{p}} \sum_{\mathrm{d} \in \mathrm{D}_{\mathrm{b}}} \mathrm{K}_{\mathrm{b}, \mathrm{p}, \mathrm{s}}\left(\lambda_{\mathrm{d}}\right) \cdot \mathrm{x}_{\mathrm{b}, \mathrm{p}, \mathrm{s}} \rightarrow \mathrm{Min}$ 


\section{Constraints for a Two-Echelon (CDC-B)}

Table 2 Constraints for a Two-Echelon Network

\begin{tabular}{|c|c|}
\hline $\begin{array}{l}\text { 1. Each } C D C \text { and } B \text { has to apply an } \\
\text { EDIMDA for each part: }\end{array}$ & $\begin{array}{l}\sum_{\mathrm{deD}} \mathrm{x}_{\mathrm{c} p \mathrm{~d}}=1 \forall \mathrm{c}, \mathrm{p} \\
\sum_{\mathrm{deD} b} \mathrm{x}_{\mathrm{b} p, d}=1 \forall \mathrm{b}, \mathrm{p}\end{array}$ \\
\hline $\begin{array}{l}\text { 2. A branch can only store a part at its } \\
\text { branch storage when the branch storage is } \\
\text { used: }\end{array}$ & 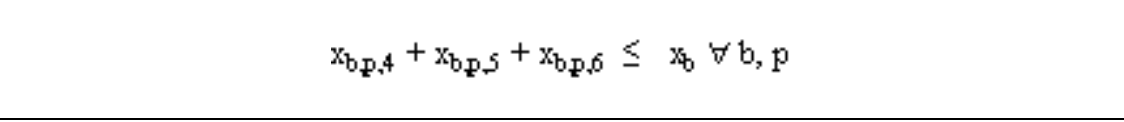 \\
\hline $\begin{array}{l}\text { 3. CDC can only supply branches when the } \\
\text { CDC stores the part: }\end{array}$ & $\mathrm{x}_{\mathrm{b}_{\mathrm{Q}, 2}}+\mathrm{x}_{\mathrm{b}_{\mathrm{Q}, 6}}+\mathrm{x}_{\mathrm{b}, 8} \leq\left(1-\mathrm{x}_{\mathrm{c}, \mathrm{p},}\right) \forall \mathrm{c}, \mathrm{b}, \mathrm{p}$ \\
\hline $\begin{array}{l}\text { 4. Each spare part must be stored in at } \\
\text { least one echelon: }\end{array}$ & $\mathrm{x}_{\mathrm{CQ}, 1}+\mathrm{x}_{\mathrm{r,p}, 2}+\mathrm{x}_{\mathrm{b}, 4}+\mathrm{x}_{\mathrm{b}_{\mathrm{Q}}, 5}+\mathrm{x}_{\mathrm{b}, 6}+\mathrm{x}_{\mathrm{b}, 8} \geq 1 \forall \mathrm{c}, \mathrm{b}, \mathrm{p}$ \\
\hline $\begin{array}{l}\text { 5. Value restriction of branch storage (cost } \\
\text { of capital restriction): }\end{array}$ & 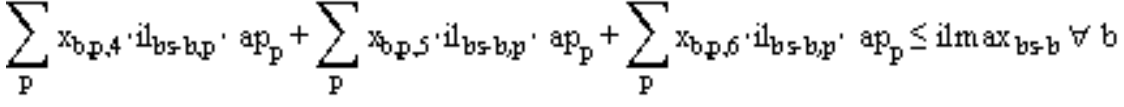 \\
\hline $\begin{array}{l}\text { 6. Value restriction of mobile storage (cost } \\
\text { of capital restriction): }\end{array}$ & $\sum_{\mathrm{p}} \mathrm{x}_{\mathrm{b}_{\mathrm{p}}, 8} \cdot \mathrm{i}_{\mathrm{rms}} \mathrm{b}^{\prime} \mathrm{ap} \mathrm{p}_{\mathrm{p}} \leq \mathrm{ilmax} \mathrm{rns}_{\mathrm{b}} \forall \mathrm{b}$ \\
\hline 7. Response times constraints: & $x_{b_{\Phi}, 1} \cdot 1 t_{s}+x_{b_{\ddagger}, 2} \cdot 1 t_{c} \leq 1 t_{b_{\ddagger}} \forall b, p$ \\
\hline 8. Binary and non-negative constraints: & $\begin{array}{c}\mathrm{x}_{\mathrm{c}, \mathrm{d}} \text { binary and } \geq 0 \forall \mathrm{c}, \mathrm{p}, \mathrm{d} \\
\mathrm{x}_{\mathrm{b}, \mathrm{d}} \text { binary and } \geq 0 \forall \mathrm{b}, \mathrm{p}, \mathrm{d} \\
\mathrm{x}_{\mathrm{b}} \text { binary and } \geq 0 \forall \mathrm{b}\end{array}$ \\
\hline
\end{tabular}

\section{APPLICATION}

To analyze the practical applicability of this model, a computational analysis has been conducted for a practical case with 1 central distribution center, 10 branches, and 1,000 spare parts. In this case, the CDC can apply each of the three CDC-EDIMDA and the branches six of the nine BDS-EDIMDA (applied BDS-EDIMDA: 1, 2, 4, 5, 6, 8), which yields 63,010 variables. For the solution of this model, a state-of-the-art commercial solver applying a branch and cut algorithm has been used, which is a wellestablished method for solving integer programming models. The problem has been solved almost to optimality within seconds and a minor optimality gap of $0.01 \%$. The computational analysis shows that a practical case can be solved in a very short time and with a high degree of quality; thus, an alternative algorithm or heuristic is not required. Since in the practical application of optimization models, the availability of data and estimation of costs are even more important, further research should address these problems. Further analysis will also be done with different network configurations with more branches and spare parts to examine the application of this model and algorithm under different conditions. Moreover, a study will be conducted to analyze the potential cost reduction resulting from this approach. The result of the optimization model is an optimized distribution plan, which can be transferred to a disposal scheduling list when combining it with the results of step 1. The disposal scheduling list should be a consolidated list of spare parts for each storage location with the optimal disposal strategy and respective parameters for each part, which minimizes the total logistics cost of the after-sales service network.

\section{CONCLUSIONS}

This paper presents an approach for the integration of real-time demand information and planning of spare parts distribution, and appropriate planning methods that aftersales service network providers can apply to find costoptimal spare parts stocking strategies. The paper illustrates the relevant approaches in the literature, and introduces spare parts stocking concepts and ordering policies. Based on this analysis, a spare parts stocking strategy tool kit and the derived EDIMDA are proposed. Finally, the paper presents the three steps of the method of the distribution planning approach, including a heuristic for approximating, parameterizing, and evaluating EDIMDA, and a binary linear optimization model for choosing EDIMDA, which can also be solved for large problem instances. A regional distribution stage can be easily integrated by adding the required constraints, since the EDIMDA are already defined. Moreover, due to the modular structure of this approach, it can be easily extended to more echelons in a similar way, when developing further EDIMDA and adjusting the optimization model. This could be considered for further research, although more than three distribution stages are not very common in after-sales service networks. However, two main questions remain for further research. The first issue is either the determination of events, such as a 
significant change in spare parts demand, that will prompt the necessity to optimize distribution planning or the determination of appropriate time intervals for applying the distribution planning method. The second issue is that this approach assumes centralized planning: all network entities support the objective of minimizing the total cost of the after-sales service network. However, due to common existing profit center structures in large scale companies, this assumption does not always hold true. Therefore, further research should also address how the respective network entities can be incentivized such that centralized decisions are supported and satisfied. Answering this question could yield a very promising integrated spare parts distribution planning approach for providers of after sales service networks.

\section{REFERENCES}

Axsäter, S. (2003). A New Decision Rule for Lateral Transshipments in Inventory Systems. In: Management Science 49 (9), pp. 1168-1179.

Axsäter, S. (2006). Inventory control. In: Springer e-books 90.

Baader, A., Montanus, S., Sfat, R (2006). After Sales Services mit produktbegleitenden Dienstleistungen profitabel wachsen. In: Karim Barkawi, Andreas Baader und Sven Montanus (Eds.): Erfolgreich mit After Sales Services. Geschäftsstrategien für Servicemanagement und Ersatzteillogistik. Berlin, Heidelberg: Springer-Verlag Berlin Heidelberg.

Baumbach, M. (2004). After-Sales-Management im Maschinenund Anlagenbau. 2. Auflage. Regensburg: Transfer-Verl.

Biedermann, H. (2008). Ersatzteilmanagement. Effiziente Ersatzteillogistik für Industrieunternehmen. 2. Aufl. Berlin [u.a.]: Springer.

Blakeley, F., Argüello, B., Cao, B., Hall, W., Knolmajer, J. (2003). Optimizing Periodic Maintenance Operations for Schindler Elevator Corporation. Interfaces 33, 01-03/2003 (1), pp. 6779.

Cohen, M. A., Agrawal, N., Agrawal, V. (2006). Winning in the Aftermarket. Harvard Business Review, May 2006.

Dekker, R., Pince, C., Zuidwujk, R., Jalil, M. N. (2013). On the use of installed base information for spare parts logistics: a review of ideas and industry practice. International Journal of Production Economics 143, pp. 536-545.

Dispan, J. (2007). Aufzüge und Fahrtreppen. Branchenstudie 2007. Hg. v. IG Metall Vorstand und RKW Rationalisierungs - und Innovationszentrum der Deutschen Wirtschaft e.V. Kompetenzzentrum.

Dombrowski, U., Winnefeld, M. (2012). Trends und Lösungsansatz "Ganzheitliche Produktionssysteme" im After Sales Service. Zeitschrift für wirtschaftlichen Fabrikbetrieb 107 (5), pp. 355-359.

Graves, S. C. (1985). A Multi-Echelon Inventory Model For A Repariable Item With One-For-One Replenishment. Management Science 31 (10), pp. 1247-1256.

Hayashi, A., Ishii, N., Matsui, M. (2009) A Theory and Tools for Collaborative Demand-to-Supply Management in the SCM Age. Operations and Supply Chain Management 2(2), pp. 111-124.

Hertz, P., Finke, G. R. (2011). State of the Art in Strategic AfterSales Field Service Network and Resource Planning in the Machine and Plant Engineering Industry. Proceedings of The 2nd International Research Symposium in Service Management. Yogykarta, Indonesia, 26.07.2011.
Ihde, G. B.; Merkel, H., Henning, R. (1999). Ersatzteillogistik. Theoretische Grundlagen und praktische Handhabung. 3. Aufl. München: Huss.

Klug, F. (2010). Logistikmanagement in der Automobilindustrie: Grundlagen der Logistik im Automobilbau. VDI-Buch. Berlin, Heidelberg: Springer-Verlag.

Kuhn, A.,; Hellingrath, B. (2002). Supply-Chain-Management. Optimierte Zusammenarbeit in der Wertschöpfungskette. Berlin, Heidelberg, New York, Barcelona, Hongkong, London, Mailand, Paris, Tokio: Springer (Engineering online library).

Meierbeck, R., Grossmann, S. (2012). Vom "Enabler" zum "Driver" - Das DMDC-Konzept von BMW als Paradigmenwechsel in der Ersatzteillogistik. In: Ingrid Göpfert, David Braun und Matthias Schulz (Eds.): Automobillogistik. Stand und Zukunftstrends. Wiesbaden: Gabler Verlag, pp. 291-310.

Muckstadt, J. A.; Sapra, Amar (2010). Principles of inventory management. When you are down to four, order more. New York: Springer (Springer series in operations research and financial engineering).

Jalil, M. N. (2011). Customer Information Driven After Sales Service Management. Lessons from Spare Parts Logistics.

Niggeschmidt, S. (2010). Ausfallgerechte Ersatzteilbereitstellung im Maschinen- und Anlagenbau mittels lastabhängiger Lebensdauerprognose. Aachen: Shaker (Forschungsberichte aus dem wbk, Institut für Produktionstechnik, Karlsruher Institut für Technologie (KIT), Bd. 155).

Pfohl, H. (2010): Logistiksysteme. Berlin, Heidelberg: Springer Berlin Heidelberg, zuletzt geprüft am 08.08.2013.

Schuh, G., Stich, V., Wienholdt, H. (2013): Ersatzteillogistik. In: Günther Schuh (Eds.): Handbuch Produktion und Management. 2. Aufl. Berlin: Springer, pp. 165-207.

Sherbrooke, C. C. (1968): Metric: A Multi-Echelon Technique for Recoverable Item Control. Operations Research 16(1), pp. 122-141.

Sherbrooke, C. C. (1986): VARI-METRIC: Improved Approximations For Multi-Indenture, Multi-Echelon Availability Models. Operations Research 34(2), pp. 311319.

Sherbrooke, C. C. (2004): Optimal inventory modeling of systems. Multi-echelon techniques. Boston: Kluwer Academic (International series in operations research \& management science, 72 ).

Slay, F. M. (1984): VARI-METRIC: An Approach to Modelling Multi-Echelon Resupply when the Demand Process is Poisson with a Gamma Prior. Logistics Management Institute. Washington, D.C.

Surjandari, I., Sudarto, S., Anggarini, S. (2010): Supplier Selection in JIT Automotive Industry: A Multivariate Approach. Operations and Supply Chain Management 3(2), pp. 88-93.

Svoronos, A.; Zipkin, Svoronos (1988): Estimating The Performance of Multi-Level Inventory Systems. Operations Research 36 (1), pp. 57-72.

Thormann, M. (2014): Spare Parts Demand Planning in After-Sales Service Networks Using Real-Time Status Information About Equipment Utilization and Service Conditions. In: Auwatanamongkol und Khemapech (Hg.): Proceedings of the 1st International Conference on Applied Science, Technology and Management for Sustainable Development. Bangkok, Thailand, 23.-25.04.2014. National Institute of Development Administration, pp. 15-22.

Vahrenkamp, R., Kotzab, H. (2012). Logistik. Management und Strategien. Unter Mitarbeit von Christoph Siepermann. 7. Aufl. München: Oldenburg Verlag.

Martin Thormann received a bachelor's degree in logistics from the faculty of mechanical engineering at the TU Dortmund University, Dortmund, Germany in 2011 and a master's degree in supply chain engineering from the H. Milton Stewart 
School of Industrial and Systems Engineering at the Georgia Institute of Technology, Atlanta, USA in 2012. He gained practical experience in logistics and supply chain management while working on consulting projects for several internationally operating companies. He was a student research assistant at the Chair of Factory Organization at the TU Dortmund University and at the Fraunhofer Institute for Material Flow and Logistics. Since November 2012, he has been working on his dissertation project at the TU Dortmund University, Dortmund, Germany under a doctoral scholarship. His research focuses on spare parts demand planning and distribution planning in after-sales service networks. Mr. Thormann is member of the Council of Supply Chain Management Roundtable Germany e. V. He received a scholarship from the CSCMP Global Education e.V. for his study abroad. 